\title{
Primary pulmonary hypertension in families with hereditary haemorrhagic telangiectasia
}

\author{
S.A. Abdalla*, C.J. Gallione ${ }^{\#}$, R.J. Barst ${ }^{\Uparrow}$, E.M. Horn ${ }^{+}$, J.A. Knowles ${ }^{\S}$, D.A. Marchuk ${ }^{\#}$, M. Letarte ${ }^{*, f}$, \\ J.H. Morse ${ }^{+}$
}

Primary pulmonary hypertension in families with hereditary haemorrhagic telangiectasia. S.A. Abdalla, C.J. Gallione, R.J. Barst, E.M. Horn, J.A. Knowles, D.A. Marchuk, M. Letarte, J.H. Morse. (C) ERS Journals Ltd 2004.

ABSTRACT: Primary pulmonary hypertension (PPH) is a rare but severe and progressive disease characterised by obstructive lesions of small pulmonary arteries. Patients with PPH often have mutations in the bone morphogenetic protein receptor type II (BMPR2) gene, whereas some carry mutations in the activin receptor-like kinase $1(A L K-1)$ gene, generally associated with hereditary haemorrhagic telangiectasia (HHT) type 2, a vascular dysplasia affecting multiple organs. The aim of this study was to determine whether members of families with PPH and confirmed or probable HHT had $A L K-1$ mutations.

$A L K-1$ and $B M P R 2$ mutation analysis was performed on deoxyribonucleic acid from affected members of four families with PPH and confirmed or suspected HHT.

$A L K-1$ mutations were identified in all four families and three novel mutations found in exon 10, leading to truncated proteins. In the fourth family, a missense mutation, previously reported in four independent HHT families, was detected in exon 8 . Analysis of the BMPR2 gene revealed no exonic mutations in the probands with both PPH and HHT.

The present data bring to 10 the number of reported families with primary pulmonary hypertension and hereditary haemorrhagic telangiectasia type 2 , representing $16 \%$ of the 61 families with known activin receptor-like kinase 1 mutations. Such mutations might predispose to primary pulmonary hypertension, and specialists should be aware of the potential link between these two disorders.

Eur Respir J 2004; 23: 373-377.
*Cancer Research Program, Hospital for Sick Children and University of Toronto, and Heart and Stroke/Richard Lewar Centre of Excellence, University of Toronto, Toronto, Canada. \#Dept of Molecular Genetics and Microbiology, Duke University Medical Center, Durham, NC, USA. Depts of "Pediatrics, ${ }^{+}$Medicine, and ${ }^{\$}$ Psychiatry, Columbia University College of Physicians and Surgeons, New York, NY, USA.

Correspondence: J.H. Morse, Columbia University College of Physicians and Surgeons, Dept of Medicine, New York, NY, USA. Fax: 12123054943

E-mail: jhm4@columbia.edu

Keywords: Pulmonary hypertension, transforming growth factor- $\beta$, vascular disorder

Received: July 232003

Accepted after revision: October 92003

This study was supported by grant HHTFY02-226 (M. Letarte) from the March of Dimes (New York, NY, USA), and by grants NIH-HL60056 (J.H. Morse) from Columbia University (New York, NY, USA) and NIHHL49171 (D.A. Marchuk) from Duke University (Durham, NC, USA).
Primary pulmonary hypertension (PPH) is a rare disease with an estimated incidence of $1-2$ cases per million population [1]. The presenting symptoms usually include fatigue, anorexia and shortness of breath, which, if left untreated, lead to a progressive increase in pulmonary arterial pressure, right ventricular failure and death [2]. The affected small pulmonary arteries and arterioles are characterised by intimal proliferation, medial hypertrophy, concentric fibrosis and the presence of plexiform lesions composed of both vascular smooth muscle cells and endothelial cells [3]. Monoclonal endothelial cell proliferation is found in the plexiform lesions of PPH but not in secondary pulmonary hypertension [4].

Recently, PPH has been found to be caused by mutations in either of two genes: the bone morphogenetic protein receptor type II gene (BMPR2) [5-7] and the activin receptor-like kinase 1 gene $(A C V R L 1$ or $A L K-1)$ [8], both members of the transforming growth factor- $\beta$ (TGF- $\beta$ ) receptor superfamily. A recent abstract reported an endoglin gene $(E N G)$ mutation in a patient with HHT and dexfenfluramine-associated $\mathrm{PPH}$ [9]. $A L K-1$ and $E N G$ are the two genes associated with hereditary haemorrhagic telangiectasia (HHT). Mutations in $A L K-1$ lead to HHT type 2 (HHT2) [10, 11], whereas mutations in $E N G$ are responsible for HHT type 1 (HHT1)
[12]. HHT is an autosomal dominant vascular disorder that occurs at an incidence of $>1$ in 10,000 population. It is characterised by vascular dysplasia with the formation of mucocutaneous telangiectases and arteriovenous malformations (AVMs) in the lung, brain and liver [13].

To date, 46 unique $B M P R 2$ mutations have been reported in patients with a family history of PPH [5-7], as well as in some patients with spontaneous PPH [14]. These mutations include missense, nonsense and frameshift mutations, as well as splice site mutations, occurring in the ligand-binding, transmembrane, kinase and cytoplasmic tail domains of $B M P R 2$. ALK-1 mutations associated with $\mathrm{PPH}$ are also of varying types and found throughout the gene [8]. Hence, the identification of mutations in both $B M P R 2$ and $A L K-1$ genes underlines the importance of the TGF- $\beta$ superfamily members in the maintenance of vascular integrity [15]. It also suggests that mutations in these related signalling pathways may lead to an imbalance in the regulation of TGF- $\beta$ /bone morphogenetic protein (BMP)-mediated signals in endothelium that are manifest as vascular dilatation in HHT and vascular obliteration/obstruction in PPH. Dysregulation of these same pathways was recently reported for various forms of nonfamilial PPH [16]. 
In the present study, $A L K-1$ and $B M P R 2$ mutation analysis was performed in four families with PPH and either known or suspected HHT. The present article reports $A L K-1$ mutations in all four PPH families and discusses the significance of these findings.

\section{Materials and methods}

\section{Study subjects}

All studies and procedures were reviewed and approved by the Columbia Presbyterian Medical Center Institutional Review Board (Columbia University, New York, NY, USA), the Research Ethics Board of the Research Institute of the Hospital for Sick Children (Toronto, Canada) and Duke University Medical Center Institutional Review Board (Duke University Medical Center, Durham, NC, USA).

The original study group consisted of a cohort of 104 families with either the familial form of PPH (two or more affected family members) or seemingly sporadic cases, referred for genetic evaluation from 1998 until January 2003. The diagnosis of PPH was made using a combination of results from echocardiography, right heart catheterisation and, when available, histological studies of the lung. The evaluation and work-up excluded other causes of $\mathrm{PPH}$, such as human immunodeficiency virus infection, connective tissue diseases and the use of appetite suppressant drugs. In four of the families (families 60, 82, 91 and 100), a definite diagnosis of HHT was made based on the Curaçao criteria [17]. Probands from the remaining 100 families did not fulfil the criteria for HHT. Careful family histories of these families failed to find any other members with HHT.

The results of cardiac catheterisation confirmed the diagnosis of PPH in probands from the four families (families 60 , 91 and 100 on site, 82 off site). Their pedigrees were prepared from medical records and interviews with family members, and are illustrated in figure 1 . The clinical features, results of right heart catheterisation and mutation analyses for the probands are illustrated in table 1.

Mutation analysis of activin receptor-like kinase 1 and bone morphogenetic protein receptor type II genes

Deoxyribonucleic acid (DNA) samples from the patients were analysed for $A L K-1$ mutations in two centres. In two of the families (families 60 and 82), coding exons of the $A L K-1$ gene were analysed by sequencing using the Open Gene Automated DNA Sequencing System II (Visible Genetics, Inc., Toronto, Canada), as described previously [18]. DNA samples from the other two families (families 91 and 100) were analysed using the BigDye Terminator Cycle Sequencing Ready Reaction (Applied Biosystems, Foster City, CA, USA) and run on an ABI Prism 3100 sequencer (Perkin Elmer, Wellesley, MA, USA). A Sequencher (version 4.1.4; Gene Codes Corp., Ann Arbor, MI, USA) was used to analyse the data. Samples with sequence changes were reamplified and resequenced for verification.

The 13 BMPR2 exons of the four probands were sequenced as previously described [5].

\section{Results}

Figure 1 illustrates the presence of HHT and PPH in the families analysed. Table 1 illustrates the clinical features, results of right heart catheterisation and mutations found in the four probands. $A L K-1$ mutations were identified in four families with both PPH and a confirmed or suspected diagnosis of HHT. The three novel mutations are predicted to lead to truncations in exon 10, whereas the fourth mutation is a previously reported missense mutation in exon 8 (table 1). None of the four probands showed exonic mutations in the $B M P R 2$ gene.
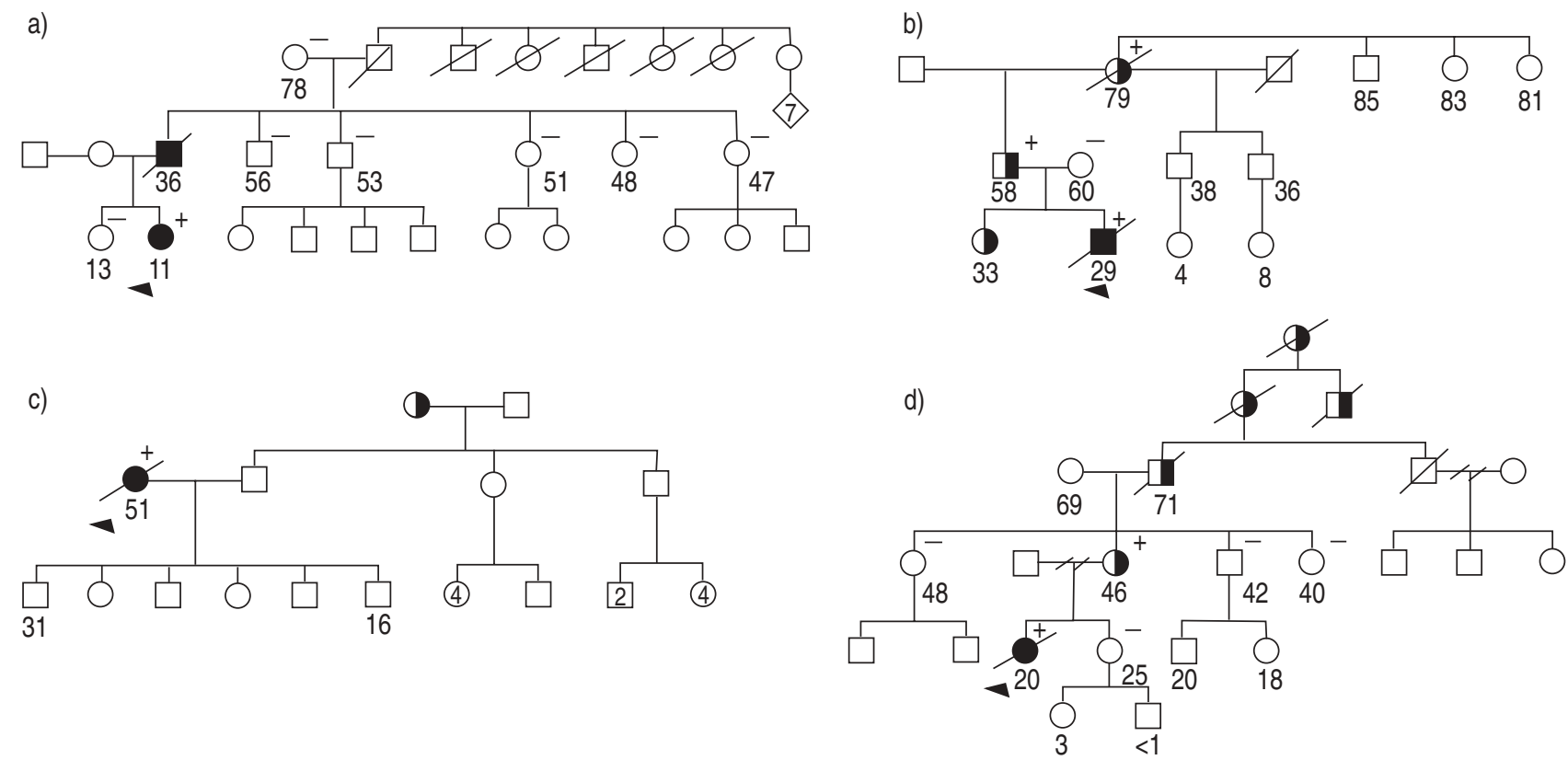

Fig. 1.-Pedigrees of the four families with primary pulmonary hypertension (PPH) and hereditary haemorrhagic telangiectasia (HHT): a) family 60 ; b) family 82 ; c) family 91 ; and d) family 100 . The numbers under the symbols $(\bigcirc$ : female; $\square$ : male; $\diamond:$ sex unknown; $\mathbf{\square}$, $\bigcirc$ : affected individuals (left half PPH; right half HHT)) indicate the age of the patients (in years) at the time of manuscript preparation or death (/); numbers within symbols represent the number of siblings of that sex (//: divorce). Arrowheads indicate probands with $(+)$ or without $(-)$ a familial germline activin receptor-like kinase 1 gene mutation as determined by sequencing. 
Table 1.-Clinical features and mutations in probands with both pulmonary hypertension (PH) and hereditary haemorrhagic telangiectasia $(\mathrm{HHT})$

Family No. of proband

\begin{tabular}{|c|c|c|c|c|}
\hline & \\
\hline & 60 & 82 & 91 & 100 \\
\hline Sex & $\mathrm{F}$ & M & $\mathrm{F}$ & $\mathrm{F}$ \\
\hline \multicolumn{5}{|l|}{ Known HHT features } \\
\hline Family history of HHT & + & + & + & + \\
\hline Epistaxis & + & + & + & + \\
\hline Telangiectasia & + & + & + & + \\
\hline Pulmonary AVM & - & NK & - & + \\
\hline Hepatic AVM & NK & NK & + & + \\
\hline Other AVM & NK & NK & GI & GI \\
\hline \multicolumn{5}{|l|}{ Known PH features } \\
\hline Age at onset yrs & 8 & $20 \mathrm{~s}$ & 43 & 18 \\
\hline Family history of PPH & + & - & - & - \\
\hline \multicolumn{5}{|l|}{ Right heart catheterisation } \\
\hline Mean $P$ pa $\mathrm{mmHg}$ & 38 & NK & 50 & 65 \\
\hline Mean $P$ ra $\mathrm{mmHg}$ & 1 & NK & 14 & 7 \\
\hline $\mathrm{CI} \mathrm{L} \cdot \mathrm{min}^{-1} \cdot \mathrm{m}^{-2}$ & 4.0 & NK & 2.8 & 2.2 \\
\hline PVRI $\mu \cdot \mathrm{m}^{-2}$ & 8 & NK & 14 & 44 \\
\hline SVRI $\mu \cdot \mathrm{m}^{-2}$ & 14 & NK & 24 & 25 \\
\hline $\mathrm{Sv}_{\mathrm{V}, \mathrm{O}_{2}} \%$ & 82 & NK & 56 & 50 \\
\hline $\mathrm{Sa}, \mathrm{O}_{2} \%$ & 99 & NK & 100 & 78 \\
\hline Acute vasodilator testing & NR & NK & NR & NR \\
\hline Epoprostenol therapy & + & + & + & + \\
\hline Outcome/age yrs & Alive/11 & Dead/29 & Dead/51 & Dead/20 \\
\hline \multicolumn{5}{|l|}{$A L K-1$ mutation } \\
\hline Exon & 10 & 10 & 8 & 10 \\
\hline Nucleic acid change & 1450C $>\mathrm{T}, 1450 \_1451 \mathrm{insG}$ & $1435 \mathrm{C}>\mathrm{T}$ & $1120 \mathrm{C}>\mathrm{T}$ & $1385 \mathrm{C}>\mathrm{G}$ \\
\hline Amino acid position & R484Wfs $\bar{X} 493$ & R479X & R374W & S462X \\
\hline Type of mutation & Insertion & Nonsense & Missense & Nonsense \\
\hline \multicolumn{5}{|l|}{ BMPR2 mutation } \\
\hline Presence/absence & - & - & - & - \\
\hline
\end{tabular}

AVM: arteriovenous malformation; PPH: primary pulmonary hypertension; $P$ pa: pulmonary arterial pressure; $P$ ra: right atrial pressure; CI: cardiac index; PVRI: pulmonary vascular resistance divided by basic surface area; $\mathrm{SVRI}$ : systemic vascular resistance divided by basic surface area; $S_{\mathrm{v}}, \mathrm{O}_{2}$ : mixed venous saturation; $\mathrm{Sa}, \mathrm{O}_{2}$ : systemic oxygen saturation; $A L K-1$ : activin receptor-like kinase 1 gene; $B M R P 2$ : bone morphogenetic protein receptor type II gene; F: female; M: male; NK: not known; GI: gastrointestinal; NR: no response; C: cytosine; T: thymine; G: guanine; >: substitution; _: range of affected residues; ins: insertion; R: arginine; W: tryptophan; fs: frameshift; X: stop codon; S: serine; +: present; -: absent.

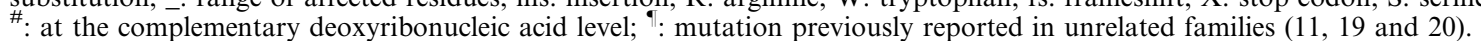

\section{Family 60}

In this family, a novel complex mutation (cytosine $(\mathrm{C})$ to thymine (T) substitution at complementary DNA base 1450 with insertion of guanine $(\mathrm{G})$ between bases 1450 and 1451 (1450C>T, 1450_1451insG)) was identified in exon 10 of $A L K-1$. It causes a substitution at amino acid 484 followed by a frameshift with truncation at residue 493 in the kinase domain (table 1). This mutation was identified in the 11-yrold proband, who is still alive and received epoprostenol therapy for PPH. This patient also had reactive airway disease, bruised easily and experienced frequent spontaneous haemorrhages from the nose, gums and skin for several years. The unaffected sibling did not carry the familial mutation. Their father, who had a history of very frequent epistaxis, was never diagnosed with HHT, but had PPH and died aged 36 yrs after lung transplant rejection (fig. 1). The lung surgical pathology report described histological features of PPH with intimal proliferation, medial hypertrophy, and concentric intimal fibrosis and plexiform lesions (Heath and Edwards grade V/VI). There was also dilatation of small pulmonary arteries and arterioles compatible with HHT. None of the father's five siblings showed symptoms of PPH or HHT nor did they carry the $A L K-1$ mutation. The familial mutation was not found in the proband's asymptomatic grandmother. DNA from the grandfather, who died of emphysema, was not available for analysis, and two of the grandfather's siblings died of pancreatic carcinoma.

\section{Family 82}

The nonsense mutation found in this PPH family was a $1435 \mathrm{C}>\mathrm{T}$ (table 1). It was detected in exon 10 of $A L K-1$ and leads to a stop codon at arginine 479. The male proband, followed in Europe on epoprostenol therapy, succumbed to PPH aged 29 yrs. The proband's father and grandmother also carried this mutation and all three patients had a confirmed diagnosis of HHT (fig. 1). The proband's sister also has HHT and no symptoms of PPH, but the sister's DNA was not available for testing.

\section{Family 91}

The missense mutation identified in exon 8 of $A L K-1$ in this family $(1120 \mathrm{C}>\mathrm{T})$ leads to substitution of arginine 374 (table 1). This mutation has been previously described as the causative mutation for HHT in four unrelated families with no reported signs of PPH $[11,19,20]$. The proband had a history of HHT and died of PPH aged 51 yrs. The proband had severe epistaxis and had undergone nasal septal dermatoplasty; 
coumadin anticoagulation, however, had to be discontinued due to the severity of the epistaxis. Abdominal ultrasonography results were consistent with multiple hepatic AVMs. Liver biopsy revealed vascular abnormalities consistent with HHT and perivascular congestion and fibrosis consistent with right heart failure. Head CT results were normal. The proband's mother also has HHT, but a detailed family history is unavailable.

\section{Family 100}

The nonsense mutation found in exon 10 in this family is a $1385 \mathrm{C}>\mathrm{G}$ causing truncation at serine 462 (table 1 ). The female proband had nosebleeds and telangiectases consistent with HHT. The proband also had multiple pulmonary AVMs: a large spontaneously thrombosed right upper lobe AVM, and AVMs in the left upper and lower lobes of the lung. Nonenhancing areas in the right lobe of the liver were compatible with thrombosed AVMs. The proband died of PPH aged $20 \mathrm{yrs}$, and was not a candidate for embolisation of the pulmonary AVMs. The proband's sister exhibited no manifestations of HHT and did not carry the mutation in the $A L K-1$ gene. The familial mutation was detected in the proband's affected mother but not in the mother's three siblings, who showed no symptoms of either PPH or HHT (fig. 1). All of the other family members affected with HHT had a history of severe nosebleeds and prominent telangiectases.

\section{Discussion}

From a cohort of $104 \mathrm{PPH}$ families initially referred for $B M P R 2$ mutation analysis, four probands with HHT were identified. They fulfilled three of the four Curaçao diagnostic criteria for HHT [16] with telangiectases, severe epistaxis and a family history of HHT. In addition, one proband (family 100) had known pulmonary and hepatic AVMs and another (family 91) hepatic AVMs. All four probands showed pulmonary arterial hypertension, the severity of which was diagnosed at cardiac catheterisation and required epoprostenol therapy.

These patients had mutations in the $A L K-1$ gene, confirming the diagnosis of HHT2. The missense mutation in exon 8 has been previously described in several HHT families [11, 19, $20]$, in which none of the patients had PPH. The three mutations in exon 10 were novel and comprised two nonsense mutations and one complex mutation that would be predicted to result in truncated proteins. It is interesting to note that 10 $(19 \%)$ of the 53 reported mutations in the $A L K-1$ gene (present in a total of 61 families) were identified in patients with PPH and clinical manifestations of HHT. In the first report of PPH in HHT families, six $A L K-1$ mutations were found, one each in exons 2, 3, 6 and 8 and two in exon 10 [8]. The new total of five exon 10 mutations in the 10 known PPH/ HHT probands suggests that this region of the protein is functionally important since its absence might predispose to pulmonary hypertension.

Two of the mutations in exon 10 fall within the conserved carboxyl-terminal region of ALK-1, which comprises residues $479-489$, and is referred to as the nonactivating nondownregulating box (NANDOR BOX) [20, 21]. The substitution $1435 \mathrm{C}>\mathrm{T}$ results in a termination codon at position 479 , thus deleting the NANDOR BOX. The complex mutation (which modifies residue 484 and subsequent residues and causes termination at residue 493) would also alter the sequence and structure of the NANDOR BOX. The third exon 10 mutation $(1385 \mathrm{C}>\mathrm{G})$ also leads to a truncated protein lacking this region. Data obtained with similar truncation mutants of the related transforming growth factor- $\beta$ (TGF- $\beta$ ) type I receptor, ALK-5, have shown that this domain is important in TGF- $\beta$-induced receptor signalling downregulation [21]. Signals inhibited in the ALK-5 mutants included induction of plasminogen-activator inhibitor-1 and fibronectin and phosphorylation of mothers against decapentaplegic, homo$\log 2$ (Drosophila) (Smad2) [21]. Thus mutations leading to truncation or deletion of the NANDOR BOX of $A L K-1$ probably impair its signalling activity, yielding a nonfunctional protein associated with HHT2 and PPH [20].

No mutations were detected in the BMPR2 gene in the four $\mathrm{PPH}$ probands with HHT. However, it is interesting to compare the potential effects of $A L K-1$ and $B M P R 2$ mutations in inducing PPH. Both ALK-1, a type I receptor, and BMPR2, a type II receptor, are serine/threonine kinases that belong to the TGF- $\beta$ superfamily. Activation of either of these receptors through TGF- $\beta$ and $\mathrm{BMP} 2 / 4$ respectively leads to phosphorylation of Smad1 and Smad5, resulting in proliferation and migration of endothelial cells [22]. These data suggest that regulation of TGF- $\beta$ /BMP-mediated endothelial pathways is critical in sustaining the vascular integrity of the pulmonary circulation.

It is difficult to differentiate clinically between the two types of HHT. Pulmonary AVMs are more frequent in patients with HHT1, although they have also been reported in patients with HHT2 [23-25]. Several reports have suggested an increased prevalence of liver involvement in families with HHT2 [26-28]. HHT2 is also associated with lower penetrance, milder phenotype and later disease onset. However, recent evidence for the association of $\mathrm{PPH}$, a severely debilitating and fatal disorder, in patients with HHT2 stresses the importance of performing molecular analysis for HHT, particularly HHT2, in PPH patients without BMPR2 mutations to identify a genetic cause for the disorder. Including the present study, there are now 10 known families with $A L K-1$ mutations and both PPH and HHT2, in contrast to the one $E N G$ mutation in the HHT1 patient with appetite suppressant PPH [9]. They represent $16 \%$ (10 of 61) of the total number of families reported with $A L K-1$ mutations and HHT2, a significant proportion.

HHT can be difficult to detect clinically, particularly in young children, as illustrated by the 11 yr-old child with PPH from family 60 . This child showed frequent epistaxis but had not developed telangiectases, which often become evident between the ages of 20 and 40 yrs [24]. In addition, the family lacked a history of HHT. A diagnosis of HHT was not entertained in her 36-yr-old father ante mortem despite $\mathrm{PPH}$, a history of severe epistaxis, and histological findings compatible with both PPH and HHT, with pulmonary plexiform lesions and dilatation of the small arterioles. In such cases, awareness of HHT symptoms in PPH patients becomes important in terms of identifying a familial condition and its potential risks. Reciprocally, clinical screening of patients known to have an $A L K-1$ mutation and their first-degree relatives may have the potential advantage of identifying markers of PPH and possibly allow earlier disease detection and intervention. Based on overall risk/benefit considerations, estimation of pulmonary arterial systolic pressure by Doppler echocardiography is currently the most useful screening tool for the detection of asymptomatic pulmonary hypertension and should be considered in HHT2 families.

Additional factors, whether genetic or environmental, may be required for the onset of PPH in subjects with mutations in either $A L K-1$ or $B M P R 2$ genes. Both diseases show autosomal dominant inheritance, but PPH families with $B M P R 2$ mutations show incomplete penetrance, and very few HHT patients with $A L K-1$ mutations develop PPH. Appetite suppressant drugs and human immunodeficiency virus infection 
are known causes of PPH [1], and mutations in $B M P R 2$ have been found in fenfluramine-associated PPH [29]. Hence, appetite suppressants may become a more widely appreciated initiator of PPH over time in both HHT1 and HHT2 [9]. VOELKEL et al. [30] hypothesised that PPH, like cancer, requires "two hits". Mutations in ether $A L K-1$ or BMPR2 genes would represent the first "hit" and predispose to vascular changes.

Future studies should determine the factors contributing to the development of primary pulmonary hypertension in patients with activin receptor-like kinase 1 or bone morphogenetic protein receptor type II mutations.

Acknowledgements. The authors wish to thank the patients, their families and the physicians who helped with the clinical aspects of this study.

\section{References}

1. Rich S, ed. Primary Pulmonary Hypertension: Executive Summary from the World Symposium on Primary Pulmonary Hypertension 1998. Geneva, World Health Organization, 1998. http://www.who.int/ncd/cvd/ph.html. Date last accessed: 11 July 2001.

2. Rubin LJ. Primary pulmonary hypertension. $N$ Engl $J$ Med 1997; 336: 111-117.

3. Loyd JE, Atkinson JB, Pietra GG, Virmani R, Newman JH. Heterogeneity of pathologic lesions in familial primary pulmonary hypertension. Am Rev Respir Dis 1988; 138: 952-957.

4. Lee SD, Shroyer KR, Markham NE, Cool CD, Voelkel NF, Tuder RM. Monoclonal endothelial cell proliferation is present in primary but not secondary pulmonary hypertension. J Clin Invest 1998; 101: 927-934.

5. Deng Z, Morse JH, Slager SL, et al. Familial primary pulmonary hypertension (Gene $P P H 1$ ) is caused by mutations in the bone morphogenetic protein receptor-II gene. Am J Hum Genet 2000; 67: 737-744.

6. Lane KB, Machado RD, Pauciulo MW, et al. Heterozygous germline mutations in $B M P R 2$, encoding a TGF- $\beta$ receptor, cause familial primary pulmonary hypertension. Nat Genet 2000; 26: 81-84.

7. Machado RD, Pauciulo MW, Thomson J, et al. BMPR2 haploinsufficiency as the inherited molecular mechanism for primary pulmonary hypertension. Am J Hum Genet 2001; 68: 92-102.

8. Trembath RC, Thomson JR, Machado RD, et al. Clinical and molecular genetic features of pulmonary hypertension in patients with hereditary hemorrhagic telangiectasia. $N$ Engl $J$ Med 2001; 345: 325-334.

9. Chaouat A, Coulet F, Simonneau G, Weitzenbaum E, Soubrier R, Humbert M. Endoglin germline mutation, hereditary hemorrhagic telangiectasia and dexfenfluramineassociated pulmonary arterial hypertension. Am J Respir Crit Care Med 2003; 167: A842.

10. Johnson DW, Berg JN, Baldwin MA, et al. Mutations in the activin receptor-like kinase 1 gene in hereditary haemorrhagic telangiectasia type 2. Nat Genet 1996; 13: 189-195.

11. Berg JN, Gallione CJ, Stenzel TT, et al. The activin receptorlike kinase 1 gene: genomic structure and mutations in hereditary hemorrhagic telangiectasia type 2. Am J Hum Genet 1997; 61: 60-67.

12. McAllister KA, Grogg KM, Johnson DW, et al. Endoglin, a TGF- $\beta$ binding protein of endothelial cells, is the gene for hereditary haemorrhagic telangiectasia type 1. Nat Genet 1994; 8: 345-351.
13. McAllister KA, Lennon F, Bowles-Biesecker B, et al. Genetic heterogeneity in hereditary haemorrhagic telangiectasia: possible correlation with clinical phenotype. $J$ Med Genet 1994; 31: 927-932.

14. Thomson JR, Machado RD, Pauciulo MW, et al. Sporadic primary pulmonary hypertension is associated with germline mutations of the gene encoding BMPR-II, a receptor member of the TGF- $\beta$ family. $J$ Med Genet 2000; 37: 741745 .

15. Massague J, Chen YG. Controlling TGF- $\beta$ signaling. Genes Dev 2000; 14: 627-644.

16. Du L, Sullivan CC, Chu D, et al. Signaling molecules in nonfamilial pulmonary hypertension. $N$ Engl J Med 2003; 348: $500-509$.

17. Shovlin C, Guttmacher A, Buscarini E, et al. Diagnostic criteria for hereditary hemorrhagic telangiectasia (Rendu-Osler-Weber syndrome). Am J Med Genet 2000; 18: 213-214.

18. Abdalla SA, Pece-Barbara N, Vera S, et al. Analysis of ALK-1 and endoglin in newborns from families with hereditary hemorrhagic telangiectasia type 2. Hum Mol Genet 2000; 9: 1227-1237.

19. Kjeldsen AD, Brusgaard K, Poulsen L, et al. Mutations in the $A L K-1$ gene and the phenotype of hereditary hemorrhagic telangiectasia in two large Danish families. Am J Med Genet 2001; 98: 298-302.

20. Abdalla SA, Cymerman U, Johnson RM, Deber CM, Letarte M. Disease-associated mutations in the conserved residues of the ALK-1 kinase domain. Eur J Hum Genet 2003; 11: 279-287.

21. Garamszegi N, Dore JJ, Penheiter SG, Edens M, Yao D, Leof EB. Transforming growth factor beta receptor signaling and endocytosis are linked through a $\mathrm{COOH}$ terminal activation motif in the type I receptor. Mol Biol Cell 2001; 12: 2881-2893.

22. Oh SP, Seki T, Goss KA, et al. Activin receptor-like kinase 1 modulates transforming growth factor-beta 1 signaling in the regulation of angiogenesis. Proc Natl Acad Sci USA 2000; 97: 2626-2631

23. Berg JH, Guttmacher AE, Marchuk DA, Porteous ME. Clinical heterogeneity in hereditary haemorrhagic telangiectasia: are pulmonary arteriovenous malformations more common in families linked to endoglin? J Med Genet 1996; 33: $256-257$

24. Shovlin CL, Letarte M. Hereditary haemorrhagic telangiectasia and pulmonary arteriovenous malformations: issue in clinical management and review of pathogenic mechanisms. Thorax 1999; 544: 714-729.

25. Abdalla SA, Geisthoff U, Bonneau D, et al. Visceral manifestations in hereditary hemorrhagic telangiectasia type 2. J Med Genet 2003; 40: 494-502.

26. Piantanida M, Buscarini E, Dellavecchia C, et al. Hereditary haemorrhagic telangiectasia with extensive liver involvement is not caused by either HHT1 or HHT2. J Med Genet 1996; 33: $441-443$

27. Lin WD, Wu JY, Hsu HB, Tsai FJ, Lee CC, Tsai CH. Mutation analysis of a family with hereditary hemorrhagic telangiectasia associated with hepatic arteriovenous malformation. J Formos Med Assoc 2001; 100: 817-819.

28. Olivieri C, Mira E, Delu G, et al. Identification of 13 new mutations in the ACVRL1 gene in a group of 52 unselected Italian patients affected by hereditary haemorrhagic telangiectasia. J Med Genet 2002; 39: E39.

29. Humbert M, Deng Z, Simonneau G, et al. BMPR2 germline mutations in pulmonary hypertension associated with fenfluramine derivatives. Eur Respir J 2002; 20: 518-523.

30. Voelkel NF, Cool C, Lee SD, Wright L, Geraci MW, Tuder RM. Primary pulmonary hypertension between inflammation and cancer. Chest 1998; 114: 225S-230S 